\title{
UNA VISIÓN SINTÉTICA DE LA PREHISTORIA DE ANDALUCÍA: NEOLÍTICO-BRONCE RECIENTE
}

\section{A SYNTHETIC VIEW OF THE ANDALUSIAN PREHISTORY: NEOLITHIC-LATE BRONZE AGE}

\author{
por \\ MANUEL PELLICER CATALÁN
}

\begin{abstract}
RESUMEN A través de la división del territorio andaluz en tres grandes círculos culturales, que de alguna manera responden en parte a áreas geográficas también diversas, se presenta en este trabajo una reflexión sobre la prehistoria de la región en la que se lleva a cabo una síntesis de la situación actual de las investigaciones y de las perspectivas de futuro.
\end{abstract}

ABSTRACT By means of the division of the Andalusian territory in three big cultural circles, which correspond to different geographical areas, this article presents a reflection on the Prehistory of the region and carries out a synthesis of the current research situation and of the perspectives for the future.

Con motivo de la celebración del II Congreso Internacional "El Estrecho de Gibraltar", celebrado en Ceuta en Noviembre de 1990, presenté una ponencia sobre Prehistoria de Andalucía, sintetizada en estas breves líneas.

El tema es tan arduo, por su vastedad geográfica y cronológica, como complejo, dado los innumerables interrogantes que a cada paso se abren. Yo me ocupé precisamente de marcar las líneas culturales desde el Neolítico, desde la aparición de las primeras sociedades productoras, hasta el ocaso de la Prehistoria con la Edad del Hierro.

Andalucía no responde en su Prehistoria a una unidad geográfica ni cultural. Geográficamente Andalucía presenta tres grandes círculos, el Oriental, sumamente montañoso, el Occidental, cuyo principal accidente es el amplio Valle del Guadalquivir, y la Costa Meridional, desde Gibraltar a Almería, participante de los círculos anteriores. 
En el Neolítico, como en la formación de cualquier otra cultura, cabría distinguir un sustrato, epipaleolítico, raramente detectado, excepto en algunos yacimientos malagueños, como las cuevas del Hoyo de la Mina y de Nerja, giennenses, como la Cueva del Nacimiento de Pontones, o almerienses, como la Cueva de Ambrosio, y, por otra parte, unas corrientes de las cuales sólo una se aprecia en Andalucía, la de la cerámica impresa o cardial, común en el Mediterráneo Occidental, que procedente, en este caso, del Levante Hispano, afecta con cierta intensidad a Andalucía Oriental, según se observa en el yacimiento de la Cueva de la Carigüela de Píñar (Granada) y con menor intensidad en el círculo de la Costa y en el Occidental, penetrando, incluso, en Portugal.

Este desmarque de Andalucía Occidental del gran círculo cardial mediterráneo occidental podría explicarse por haberse conformado allí, según los datos que vamos recopilando, otro foco, distinto, independiente del Mediterráneo en ciertos aspectos.

Esta singularidad de los arcaicos inicios del Neolítico de Andalucía Occidental está respaldada por varios fenómenos: por la secuencia evolutiva de la industria lítica de características microlaminares y de raíces claramente epipaleolíticas locales; por la presencia de vasos de arcilla sin cocer y con improntas de cestería en su superficie externa, procedentes de niveles epipaleolíticos, fechados con el C 14 en el VII milenio a. C. en la Cueva de Nerja; por la posibilidad de la existencia de cerdos domésticos en niveles epipaleolíticos avanzados de esa misma cueva; por corresponder las primeras cerámicas de las cuevas excavadas de esa especie denominada a la almagra, aparecida con profusión y con calidad excepcional, diversa en motivos y técnicas decorativas a las del resto del Mediterráneo Occidental; y, finalmente, por las altas cronologías, dentro del VI milenio a.C., de los niveles correspondientes de las tres estratigrafías practicadas por nosotros, cuevas de Nerja (Málaga), de la Dehesilla (Cádiz) y de Santiago Chica (Sevilla).

El Neolítico Andaluz ya fue conocido en el pasado siglo a través de las cuevas de los Murciélagos de Albuñol (Almería) y de la Mujer de Alhama de Granada, pero fue P. Bosch quien lo teorizó en los años veinte con la denominación de la "Cultura de las Cuevas", terminología que siempre he repudiado por inexacta y confusa. Precisamente, conforme avanza las prospecciones, se multiplican los yacimientos neolíticos al aire libre con cerámicas a la almagra, cardiales, incisas, etc. y de una especial manera en la Baja Andalucía y Portugal.

En Andalucía Oriental el yacimiento que ha servido de guía sobre el Neolítico es la Cueva de la Cariguiela, cuya periodización yo publiqué en 1964 y últimamente he reformado profundamente. Andalucía Occidental, donde hasta hace unos veinticinco años se extendía un gran vacío, hoy día es, quizás, la zona geográfica hispana más completa y mejor conocida estratigráficamente $\mathrm{y}$, por otra parte, donde más análisis de fauna y de $\mathrm{C} 14$ se han practicado.

Si, según parece, el Neolítico de Andalucía Occidental es el más arcaico de la Península, sin embrago, la producción agrícola se inicia en momentos posteriores al Levante (neolítico cardial de la Cueva de l'Or), ya que los análisis de cereales demuestran una aparición en el Neolítico Medio, a finales del V milenio, en la Cueva de los Murciélagos de Zuheros (Córdoba) y en el Neolítico Reciente, a finales del IV milenio a.C. en la Cueva de Nerja (Málaga), con la especie ya perfectamente seleccionada de la espelta.

Prescindiendo de posibles relaciones paleolíticas entre Iberia y el Norte de Africa, parece plausible admitir, a juzgar por las cerámicas, un influjo peninsular hacia Orán, según G. Camps, y hacia el Estrecho, según se observa en el estrato inferior de la cueva marroquí de Caf-Taht-el Gar, correspondiente al neolítico medio de la costa andaluza. 
Periodizando, con bases estratigráficas y teniendo en cuenta las fechas del C 14, tendríamos en Andalucía un Neolítico Antiguo entre el 5.500 y el 4.500, un Neolítico Medio entre el 4.500 y el 3.500 y un Neolítico Reciente entre el 3.500 y el 2.800 a.C., bien entendido que en determinadas estratigrafías todavía podría aquilatarse con más precisión, estableciendo subfases.

Si existen indicios de una evolución epipaleolítica en el Neolítico de Andalucía Occidental, lo mismo podría creerse respecto al Calcolítico. En efecto, en el Calcolítico Andaluz, posiblemente el más arcaico peninsular, se advierten fenómenos de evolución y de contactos exteriores. Con un elenco de poblados calcolíticos andaluces y portugueses estudiados, dotados de defensas, con fortificaciones de murallas y torres circulares de piedra, mucho mayor que el de hace una treintena de años, y desacreditadas en parte por C. Renfrew las teorías difusionistas a ultranza del orientalismo calcolítico, es ya obligatorio creer en la fuerza del sustrato y del autoctonismo, máxime si tenemos en cuenta un sensacional hallazgo de un yacimiento con murallas y torres circulares de piedra estudiado en Lebrija (Sevilla), sorprendentemente del Neolítico Medio, del V milenio a.C.. Por otra parte, el megalitismo, abandonada ya la idea de su origen en el Mediterráneo Oriental o en el Egeo, y aceptando las altas fechas del C 14, habría que admitir esta cultura con raíces atlánticas, portuguesas, bretonas o británicas hacia el V o IV milenio a.C. dentro de un neolítico.

La industria microlítica geométrica, tan característica de ciertas facies epipaleolíticas del Mediterráneo Occidental y latente en otras facies neolíticas del Levante y Andalucía, reaparece vigorosamente en el Calcolítico Andaluz con ciertas modificaciones tipológicas.

Resulta verdaderamente problemático catalogar con el epíteto Neolítico o Calcolítico a cietos horizontes culturales de tipo transicional, donde determinados elementos típicos de una u otra cultura se entremezclan. La presencia o ausencia de cobre no define al Calcolítico Inicial, ya que es un elemento insignificante y despreciable en relación con otros de tipo material o espiritual, como sucede en el predinástico egipcio. Exista o no metalurgia del cobre en el Calcolítico Antiguo Andaluz, éste queda completamente confirmado por la presencia de vasos cerámicos de gran volumen y de menor calidad que en el Neolítico, dotados raramente de decoración, o, si ésta existe, degenerada, siempre con las consiguientes excepciones posteriores, como ciertos vasos decorados de los Millares, pintados o incisos con motivos simbólicos de ramiformes o esteliformes.

En la sintomatología calcolítica andaluza se incluyen con gran rareza las técnicas decorativas cerámicas de las llamadas pastillas repujadas, cuya distribución geográfica forma un arco que va desde la Sierra Morena (Cueva Chica de Santiago) hasta el Languedoc, pasando por Portugal, Extremadura, Valle del Duero, Burgos, País Vasco y Cataluña. En el Calcolítico Andaluz Occidental y Portugués se hunde también la raíz de la técnica de la retícula bruñida, que tanto proliferará un milenio después en el mundo tartesio.

Las formas de vasos abiertos con sus variantes de platos, tanto carenados como de borde almendrado, tienen igualmente su cuna en el Calcolítico del Suroeste, bien entendido que los primeros, los carenados, arrancan de un momento del neolítico reciente, transicional, según se comprueba en nuestras estartigrafías y en yacimientos portugueses al aire libre. Definitivamente es obligado prescindir de esa terminología de vasos coloniales, los copos portugueses de Vilanova, o vasos cilíndricos con decoraciones incisas de zig-zags verticales paralelos, que, aunque con ciertas analogías formales con los del Cicládico Antiguo, no mantienen ninguna relación con ellos, sino, más bien, a nuestro juicio, con vasos similares del Neolítico Reciente de la estratigrafía de la Cueva de la Dehesilla. 
Con el Calcolítico se desvelan los primeros documentos de la industria textil propiamente dicha, de lana o lino, constatada por la abundancia de los "pondera" de barro de formas diferentes, rectos o curvos, de sección rectangular o circular, siempre con los extremos perforados.

La industria lítica en el Calcolítico Andaluz tenderá sorprendentemente hacia la macroindustria de tipo campiñoide, frecuentemente confundida con la paleolítica, la de tipo laminar de grandes hojas, con o sin retoques, y la microindustria de geometrismos y foliáceos, o puntas de flecha de talla bifacial, de base recta o cóncava en Andalucía Occidental y con pedúnculo y aletas en la Oriental.

La figura humana con atribuciones religiosas se representa en el arte parietal esquemático y en los llamados ídolos, de hueso, marfil, piedra o cerámica, alcanzando, en ocasiones, un acendrado naturalismo. En la actualidad se conservan severas dudas sobre sus conexiones egeas u orientales.

Definitivamente con el Calcolítico se tiende a la concentración del poblamiento en grandes establecimientos en puntos estratégicos, dominando extensas zonas fértiles y dotados de defensas artificiales, cuyas conexiones y orígenes orientales y egeos se están descartando, a pesar de su atractiva situación en cuencas de amplios ríos, abiertas hacia el mar, como el Tajo, Guadiana, Guadalquivir, Andarax y Almanzora, con algunas penetraciones hacia el interior.

El enterramiento adopta derfinitivamente el colectivismo con variedad de monumentos megalíticos y cuevas artificiales, cuyas tipologías y técnicas constructivas deben mucho más a la geología y topografía del medio que a una simple evolución.

Si en el Neolítico Andaluz se sospechaban relaciones con el Norte de Africa por los motivos y técnicas decorativas de las cerámicas, en el Calcolítico avanzado estas relaciones están ya definitivamente confirmadas por la presencia de marfil, con el que se fabrican peines, ídolos, sandalias votivas, botones con perforaciones en $\mathrm{V}$, etc. y por las cuentas de huevo de avestruz, mientras que en Norte de Africa se introduce el campaniforme hispano.

La vieja periodización calcolítica de Millares I y II, sincrónica de la cultura portuguesa de Vilanova, ha sido superada con la introducción de nuevas fases, de las que la inicial en Andalucía Occidental sería anterior a Millares, terminando con un campaniforme de un momento muy debatido, a falta de estratigrafías que lo constaten. En Andalucía Oriental este problema está resuelto con la perfecta estratigrafía del Cerro de la Virgen de Orce. Es muy plausible que en Andalucía Occidental, región innovadora de culturas y, por otra parte, decididamente conservadora, el Calcolítico durase más de un milenio, desde la primera mitad del III milenio hasta mediados del II milenio a.C., implantándose un horizonte cultural crítico epicampaniforme.

El Bronce Antiguo y Pleno, descubierto y definido en Almería por los hermanos Siret hace más de un siglo con el principal yacimiento epónimo de El Argar, se consideró difundido por toda la Península, hasta que M. Tarradell lo circunscribió y limitó solamente al Sureste Hispánico. B. Blance y H. Schubart intentaron periodizarlo en función de sus elementos funerarios. Posteriormente W. Schüle en Orce y H. Schubart y O. Arteaga en Fuente Alamo precisaron su periodización y cronología, admitiéndose en la actualidad un Argar A, B y un bronce Tardío que cabalga hacia el bronce Final.

Ultimamente V. Lull con la metodología de la llamada "nueva arqueología" y utilizando las mismas fuentes que sus predecesores, ha planteado la cultura del Argar de forma que la considera como un mero producto de evolución del Calcolítico, sin tener en cuenta, al menos en su fase antigua, los generales paralelismos de le Edad del Bronce Europea y Mediterránea, cuyo comportamiento análogo parece evidente, constatado por las grandes vías comerciales. Naturalmente puede seguirse una evolu- 
ción del sustrato calcolítico, pero de ningún modo pueden olvidarse las corrientes e intercambios de ideas o interacciones culturales. El comercio lo basa primordialmente en la frecuencia del caballo en las fases avanzadas, pero este animal más bien parece integrado en la dieta alimenticia. La intensidad de la agricultura argárica la fundamenta en la invención del arado, pero este instrumento todavía no está suficientemente constatado en el Argar. De la metalurgia deduce opulencia y, en consecuencia, desigualdad social, pero la lucha de clases, impensable, bajo mi punto de vista, en el Argar, no sería promovida exclusivamente por la metalurgia, sino por otros factores económicos más vitales como la agricultura y la ganadería. Finalmente el hundimiento del Argar no debe atribuirse de ningún modo al agotamiento de las minas, explotadas posteriormente, ya que más bien se trataría de un fenómeno muy general aplicable, incluso, a zonas no mineras como el Levante. Este fenómeno catastrófico de finales del II milenio, hacia el S. XII a.C., se constata igualmente hacia Oriente con la ruína de Micenas, de Troya y del Imperio Hitita y con las invasiones dorias, de los pueblos del mar y de los frigios. En Europa se refleja con la aparición de los campos de urnas y en la Península con la introducción del rito de la incineración en el Noreste, con el acrecentamiento de la metalistería del Bronce Atlántico y el afianzamiento de la cultura de Cogotas I y, en Andalucía Occidental, con la aparición del fenómeno tartésico.

Curiosamente en Andalucía el final del Bronce Pleno está marcado por dos hechos significativos, mientras en la parte Oriental se hunde el Argar y se enrarece profundamente el poblamiento, en la Occidental se inicia una eclosión poblacional con el surgimiento de los poblados tartésicos. Este panorama, por el contrario, contrasta vivamente con el anterior de mediados del II milenio, cuando la magnificiencia de lo argárico de Andalucía Oriental está en discordancia con el pauperismo del Bornce Pleno de Andalucía Occidental, donde apenas contamos con media docena de asentamientos conocidos, como Setefilla, El Berrueco (Medinasidonia) o el Trastejón (Huelva).

La arquitectura del Argar fue una de la más avanzadas de Occidente con vías a la implantación del urbanismo, con viviendas amplias de piedra y adobe, de planta rectangular, capaces de engendrar calles rectas y con poderosas defensas, cuyo general influjo hacia Levante y Valle del Ebro parece evidente. Este protourbanismo argárico no deja igualmente de constratar con el arcaismo del bronce pleno de Andalucía Occidental que conserva en la vivienda módulos calcolíticos, como la casa de adobes de planta de tendencia circular.

El rito del enterramiento colectivo calcolítico en suntuosos monumentos megalíticos se tronca en el vulgar enterramiento individual, sumamente variado en tipología en Andalucía Oriental y monótono en la Occidental, reducido a la simple cista extramuros, o en necrópolis aisladas.

La metalurgia y metalistería del Argar, creo que ha sido supervalorada, presentándose realmente depauperada en comparación con la de otras culturas coetáneas centroeuropeas o itálicas. Por otra parte el bronce no es tal metal, sino cobre arsenicado, por defecto de yacimientos andaluces de estaño, generalizándose la metalurgia de la plata en Andalucía Occidental.

El comercio del metal adquiere un especial incremento y la ampliación de las redes se constata por la presencia de cuentas de pasta vítrea en Fuente Alamo, quizás de origen micénico, observándose un decaimiento general de la corriente norteafricana con la disminución de objetos de marfil y la ausencia de cuentas de huevo de avestruz.

La cerámica se uniformiza, no solamente en la Península sino en casi todo el Occidente, con tendencia a la pérdida de la decoración, con formas en las que predominan los vasos carenados, siendo características en Andalucía Oriental las copas. 
El Bronce Reciente, prácticamente desconocido antes de los años sesenta, se nos presenta hoy como una cultura con entidad propia y altamente prometedora para la investigación. Los trabajos iniciados en el yacimiento del Cerro del Real de Galera y en Carmona, donde se constató estratigráficamente esta cultura, fueron continuados en Andalucía Oriental en Monachil, Purullena, Pinos Puente, Moraleda y Cuevas de Almanzora principalmente y en Andalucía Occidental en Huelva, Córdoba, Lora del Río, Montoro y Medinasidonia, etc.. Con los datos proporcionados por las estratigrafías de estos yacimientos podemos presentar ya una panorámica del Bronce Reciente Andaluz bastante completa por lo que se refiere a periodización y características, pero muy incompleta en cuanto a urbanismo y enterramiento, por no existir excavaciones en extensión o en horizontal, si exceptuamos los Cabezuelos de Ubeda y Acinipo.

Con el Bronce Reciente se observa, en principio, cierto renacimiento del viejo sustrato calcolítico, interferido en Andalucía Oriental por el quiste del Argar. Este renacimiento fue más vigoroso en Andalucía Occidental, de donde parece que arrancó la nueva cultura. En cuanto a la cerámica, afloran los viejos motivos decorativos geométricos del campniforme y las arcaicas técnicas de la retícula bruñida y de la pintura, a la vez que en Andalucía Oriental la vivienda de adobe de planta oval o circular desplaza a las consistentes casas argáricas de zócalos de piedra y de planta rectangular, por influjo quizás de la parte Occidental. En orfebrería el oro sustituye a la plata.

Siendo una época de crisis y movimientos de pueblos, ocasionados quizás por el cambio climático, es normal que puedan definirse corrientes culturales como la atlántica, que asume un especial protagonismo con la introducción de una nueva y variada panoplia armamentística de bronce auténtico, especialmente de espadas y hachas, invadiendo toda la Península, pero con más incidencia en la mitad occidental. Pese a la ausencia de hachas, el más rico exponente es el depósito de la Ría de Huelva.

La fíbula de codo, argumento constantemente esgrimido para constatar la influencia oriental precolonial, más bien parece de influencia itálica o siciliana, del mismo modo que la cerámica con incrustaciones de botones de bronce o ámbar, materia de problemático origen, báltico o mauritano.

Más que otro círculo peninsular, Andalucía sufre el influjo, no sabemos si también con matices poblacionales o simplemente comerciales, de las cerámicas meseteñas de boquique y excisas de Cogotas I, de cronologías muy elevadas, del S. XIII o XII en sus inicios, mientras se despliega, débil al principio y afianzado con el cambio del milenoio, el fenómeno tartésico del Bajo Guadalquivir y Huelva, que expandirá su influencia, representada por sus vasos carenados bruñidos y pintados, por Andalucía Oriental e incluso por Extremadura y la Meseta Sur. Frente a la teoría clásica, yo tengo la sospecha de un posible foco, tartesio, muy arcaico, de esas técnicas cerámicas de boquique y excisa en la comarca de Lebrija (Quincena), derivadas, in situ, del campaniforme, como un fenómeno análogo y paralelo al de Cogotas I meseteño.

Creo que, en aras de la claridad, sería conveniente modificar la terminología en uso, sustituyendo los epítetos Bronce Tardío-Final por el de Bronce Reciente, simplemente, con sus correspondientes fases.

El problema del enterramiento, desaparecida, al parecer, la cista del Bronce Pleno, sigue acuciante por la ausencia de documentación arqueológica suficiente. En Andalucía Oriental los enterramientos, de incineración en urna dentro de hoyo o cista que estudió L. Siret, están en entredicho respecto a su origen y cronología. Respecto a su origen, no parecen relacionables con los campos de urnas catalanes o del Ebro, por la naturaleza y tipología de los materiales, que más bien apuntan a lo tartesio y por el gran vacío levantino intermedio, y, respecto a la cronología, las urnas y ajuares se enmarcan en una cronología tardía, quizás del S. VII a.C.. Lo mismo podría pensarse de las necrópolis de incineración de Crevillente, Cerro de Alcalá de Torres (Jaén), Cortijo de la Torre de Menjibar, los Praditos de Aracena y de Medellín. 
Entre tanto, en Andalucía Occidental disponemos simplemente de las estelas grabadas, supuestas superestructuras de unos enterramientos que jamás fueron hallados, por lo que desconocemos los ritos, si fueron de incineración, de inhumación o fluviales, como se ha apuntado. No obstante, el carácter atlántico de las panoplias de las estelas parece más plausible que el mediterráneo, por algunos autores mantenido.

En principio, yo propuse una periodización del Bronce Reciente, con unas características específicas para cada zona de Andalucía, Oriental y Occidental o Tartésica, con una fase I de finales del II milenio, una fase II correspondiente al primer cuarto del I milenio y una fase III, ya del hierro y fuertemente aculturada por la colonización semita, enmarcada en el segundo cuarto del I milenio y dividida en dos subfases A y B, correspondiente a la entrada de Andalucía en la protohistoria. 